\title{
Correction to: Phonological awareness in Arabic: the role of phonological distance, phonological-unit size, and SES
}

\author{
Elinor Saiegh-Haddad ${ }^{1,2} \oplus \cdot$ Abeer Shahbari-Kassem $^{2} \cdot$ Rachel Schif $^{1}$
}

Published online: 15 July 2020

(c) Springer Nature B.V. 2020

\section{Correction to: Reading and Writing (2020) 33:1649-1674. https://doi.org/10.1007/s11145-020-10019-3}

This article should be considered to be part of the special issue but was accidentally published in a regular issue (Volume 33, Issue 6) of this journal. We apologize for the error. The article and their full references are listed below.

Saiegh-Haddad, E., Shahbari-Kassem, A., \& Schif R. (2020). Phonological awareness in Arabic: the role of phonological distance, phonological-unit size, and SES. Reading \& Writing, 33, 1649-1674. https://doi.org/10.1007/s11145-02010019-3.

Publisher's Note Springer Nature remains neutral with regard to jurisdictional claims in published maps and institutional affiliations.

The original article can be found online at https://doi.org/10.1007/s11145-020-10019-3.

Elinor Saiegh-Haddad

Elinor.Saiegh-Hadadd@biu.ac.il

1 Department of English Literature and Linguistics, Bar-Ilan University, Ramat Gan, Israel

2 The Arab Academic College of Education, Haifa, Israel 